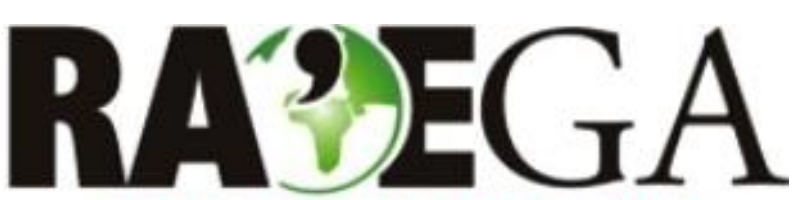

O ESPAÇO GEOGRÁFICO EM ANÁLISE

\title{
DINÂMICA DA ALTERAÇÃO DA COBERTURA VEGETAL E USO DA TERRA COM SUPORTE DE GEOTECNOLOGIA NA BACIA HIDROGRÁFICA DO RIO DESQUITE - SC
}

\section{DYNAMICS OF THE ALTERATIONS OF VEGETAL COVER AND LAND USE WITH THE SUPPORT OF GEOTECHNOLOGY IN THE DESQUITE WATERSHED-SC}

\author{
Adriana Berlanda ${ }^{1}$, Carolina Natel de Moura², Eder Alexandre Schatz Sá ${ }^{3}$, Leonardo Josoe Biffi ${ }^{4}$, \\ Valter Antonio Becegato ${ }^{5}$
}

\section{RESUMO}

Estudos relacionados à caracterização temporal do uso e ocupação da terra são indispensáveis para a definição de políticas públicas de ordenamento territorial, permitindo compreender a dinâmica de ocupação dos territórios e como esta afeta os recursos hídricos de uma bacia hidrográfica. A demanda por água é crescente, e a manutenção de sua qualidade nos mananciais é um desafio devido ao avanço da urbanização para as áreas vizinhas e áreas de recarga dos mananciais, além de intervenções nos ambientes naturais para atividades econômicas. Faz-se importante a avaliação dos impactos ambientais nestes espaços, de forma a buscar dados importantes sobre o ambiente da bacia hidrográfica e nortear ações efetivas para melhor manter e aproveitar os recursos naturais. Este trabalho apresenta uma análise espaço temporal da dinâmica do uso e ocupação da terra na bacia hidrográfica do rio Desquite, no município de Otacílio Costa, Estado de Santa Catarina, entre os anos de 1976 a 2016. Partindo da classificação de imagens de satélite, foi analisada a evolução da ocupação territorial. Em comparação dos usos e legislação ambiental pertinente, constatou-se uma redução progressiva das áreas de vegetação nativa e o avanço, principalmente, das áreas destinadas à silvicultura, inclusive no entorno de cursos d'água. A evolução da alteração do uso do terra aconteceu de forma acelerada principalmente nos períodos entre 1976 e 2006. Como resultado da análise de conflitos de uso em APPs, os resultados mostraram que 55,90\% das faixas marginais de cursos d'água estão ocupadas com classes diversas da mata nativa.

Palavras-chave: uso e ocupação da terra; sensoriamento remoto; área de preservação permanente.

\section{ABSTRACT}

Studies related to the temporal characterization of land use and occupation are indispensable for defining public policies of territorial ordering, allowing to understand the dynamics of the territories occupation and how it affects the water resources of a watershed. The demand for water is increasing and the maintenance of its quality in the springs is a challenge due to the urbanization advance to the neighboring areas and areas of springs recharge, besides interventions in the natural environments for economic activities. This work shows a detailed spatiotemporal analysis of the land use dynamics and occupation in the Desquite watershed, in the municipality of Otacílio Costa, state of Santa Catarina, from the years 1976 to 2016. From the classification of Landsat satellite images, the evolution of the territorial occupation was analyzed comparing the uses and the environmental laws regarding the Areas of Permanent Preservation. A progressive reduction of the areas of native vegetation was noticed, as well as an increase of areas destined to silviculture, including around watercourses. The evolution of the alteration of land use happened rapidly, especially in the periods between 1976 and 2006. As a result of the analysis of conflicts of use in APPs, the results showed that $55,90 \%$ of the strips around water courses are occupied with diverse classes of native vegetation.

Key-words: land use and occupation; remote sensing; area of permanent preservation

Recebido em: 15/12/2016

Aceito em: 20/02/2018

\footnotetext{
1 Universidade do Estado de Santa Catarina, Florianópolis/SC, e-mail: berlandaadriana@gmail.com

2 Universidade do Estado de Santa Catarina, Florianópolis/SC, e-mail: carolina.natel@hotmail.com

3 Universidade do Estado de Santa Catarina, Florianópolis/SC, e-mail: eder.alexandre.ef@hotmail.com

${ }^{4}$ Universidade do Estado de Santa Catarina, Florianópolis/SC, e-mail: leonardo.biffi@udesc.br

${ }^{5}$ Universidade do Estado de Santa Catarina, Florianópolis/SC, e-mail: valter.becegato@udesc.br
} 


\section{DINÂMICA DA ALTERAÇÃO DA COBERTURA VEGETAL E USO DA TERRA COM SUPORTE DE GEOTECNOLOGIA NA BACIA HIDROGRÁFICA DO RIO DESQUITE - SC}

\section{INTRODUÇÃO}

A gestão e o planejamento dos recursos hídricos têm como unidade territorial de gestão, a bacia hidrográfica (BRASIL, 1997), a qual é influenciada diretamente pelo uso e ocupação da terra. A ocupação do território pode impactar os diversos processos hidrológicos e afetar a disponibilidade de água de uma região. A demanda por água é crescente, e a manutenção de sua qualidade é um desafio devido ao avanço da urbanização para as áreas vizinhas e áreas de recarga dos mananciais, juntamente com as intervenções nos ambientes naturais para atividades econômicas, a segurança hídrica estende o conceito de disponibilidade não somente às pessoas, mas também aos ecossistemas (MANTOVANI, 2016, p.190). Sendo assim, a caracterização do meio físico da bacia hidrográfica é condição básica para um planejamento bem sucedido da conservação e produção de água, com o intuito de levantar todas as áreas críticas do ponto de vista da manutenção da água (PINTO, 2005, p.49; COSTA, 2007, p.21; COUTINHO, 2013, p.425; OLIVEIRA, 2015, p.49).

Nas últimas décadas tem se dado bastante destaque a utilização de sensoriamento remoto no monitoramento e avaliação da dinâmica do uso e ocupação da terra. A utilização do SIG cria materiais que podem servir como base em tomadas de decisões pelo Poder Público, assim como auxilia o desenvolvimento de projetos ambientais nas empresas privadas (CARVALHO, 2014, p.3).

A análise multitemporal de padrões de mudança no uso e ocupação do solo a partir de dados de satélites da série Landsat fornecem de forma precisa e econômica informações relevantes para a tomada de decisão em gestão ambiental (YUAN et al., 2005, p.317). Segundo Prina \& Monguilhott (2011, p.3812) o uso de imagens de satélite facilita os estudos de impactos ambientais, pois proporciona o trabalho simultâneo de grandes volumes de dados e a análise de áreas com grandes extensões, além de proporcionar a análise dos impactos da ação antrópica sobre os recursos naturais.
Com o aumento da disponibilidade das imagens de alta resolução e o avanço de técnicas e ferramentas automáticas capazes de interpretar a massa de dados produzida, essas imagens tendem a ser cada vez mais utilizadas para se extrair informações remotamente da superfície terrestre, como o uso e cobertura da terra, através de métodos de classificação, que reconhecem padrões (CAMPOS, 2013, p.8035).

Estes levantamentos são considerados importantes ferramentas na construção de indicadores ambientais e para a avaliação da capacidade de suporte ambiental, visto que proporcionam o conhecimento dos diferentes manejos empregados e identificam alternativas que permitem o desenvolvimento sustentável (IBGE, 2013, p.37).

Assim, buscou-se no presente estudo, avaliar através de dados de sensoriamento remoto e geoprocessamento em ambiente SIG, a evolução do uso e ocupação da terra no decorrer dos últimos 40 anos, do ano de 1976, a cada 10 anos, até 2016, analisando os desdobramentos das ações antrópicas na área total e particularmente nas Áreas de Preservação Permanente da bacia hidrográfica do rio Desquite. “Áreas de Preservação Permanente são fundamentais para a manutenção da vegetação nativa de determinadas regiões com o objetivo de manter equilibrado o uso do solo, que deve estar coberto pela vegetação original (MOREIRA, et al., 2015, p. 142)." Com isso, objetiva-se fornecer informações que balizem políticas públicas e ações civis voltadas à preservação e equilíbrio dos sistemas ambientais e quando necessário, sua recuperação.

\section{MATERIAIS E MÉTODOS}

As bases digitais utilizadas para a execução deste estudo foram obtidas do aerolevantamento de Santa Catarina realizado pela Secretaria de Desenvolvimento Econômico e Sustentável deste estado durante o período de 2010 a 2012 (SDS, 2013): Ortofotos geradas a partir de um conjunto de fotografias aéreas, com resolução espacial de $39 \mathrm{~cm}$ e escala de 1:10.000; Modelo Digital de Terreno (MDT) oriundo de 


\section{DINÂMICA DA ALTERAÇÃO DA COBERTURA VEGETAL E USO DA TERRA COM SUPORTE DE GEOTECNOLOGIA NA BACIA HIDROGRÁFICA DO RIO DESQUITE - SC}

restituição aerofotogramétrica, com resolução (pixel) de $0,4 \mathrm{~m}$ e resolução espacial de $1,0 \mathrm{~m}$ e Rede hidrográfica consolidada com escala de 1:10.000. Além de mapas temáticos disponibilizados pela EMBRAPA (2004). Os dados foram tratados em software de geoprocessamento e permitiram realizar a delimitação da área, o traçado do perímetro e o realce da rede de drenagem com base em critérios topográficos e hipsométricos (Figura 1). A base cartográfica foi organizada através do Sistema de Coordenadas Geográficas utilizandose o Datum SIRGAS2000.

Utilizou-se, para a classificação de usos da terra, Imagens Digitais disponibilizadas no catálogo de imagens do Serviço Geológico dos Estados Unidos (USGS), provenientes dos satélites: Landsat 2/MSS, 5/TM e 8/OLI, cujos metadados estão apresentados na Tabela 1. As imagens foram tratadas em softwares de geoprocessamento (Figura 1). "Tais conjuntos de dados multitemporais são indispensável para a compreensão do passado na dinâmica de ocupação do solo e na previsão das implicações futuras das mudanças no fornecimento e gestão dos serviços dos ecossistemas (SEXTON, 2013, p.246)".

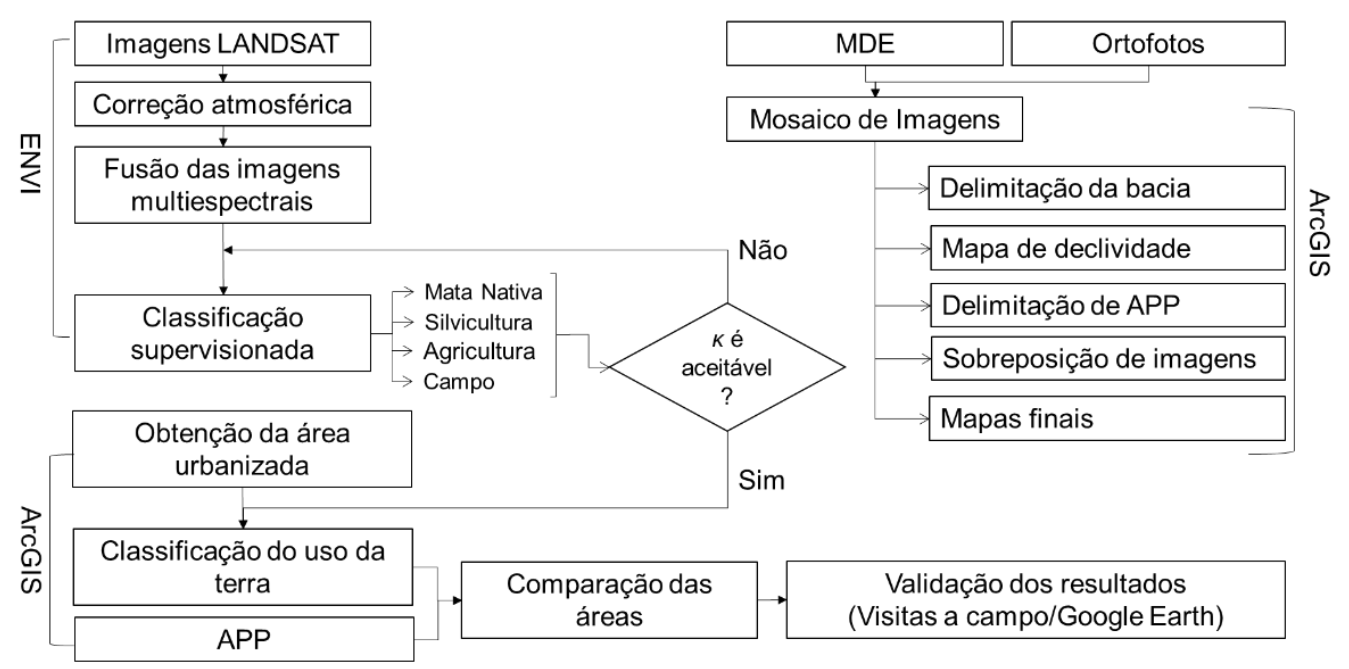

Figura 1 - Fluxograma dos processos realizados em ambiente SIG. Fonte: Autor.

Tabela 1 - Metadados das imagens utilizadas para a classificação de usos da terra.

\begin{tabular}{|c|c|c|c|c|c|}
\hline Data & Satélite & Sensor & Bandas Espectrais & $\begin{array}{c}\text { Resolução } \\
\text { Espacial }\end{array}$ & $\begin{array}{c}\text { Resolução } \\
\text { Radiométrica }\end{array}$ \\
\hline 09/11/1976 & $\begin{array}{c}\text { Landsat } \\
2\end{array}$ & MSS & $\begin{array}{c}\text { Banda } 1 \text { Verde } \\
\text { Banda } 2 \text { Vermelho }\end{array}$ & $80 \mathrm{~m}$ & 4 bits \\
\hline $\begin{array}{l}23 / 10 / 1986 \\
04 / 01 / 1996 \\
12 / 09 / 2006\end{array}$ & $\begin{array}{c}\text { Landsat } \\
5\end{array}$ & TM & $\begin{array}{c}\text { Banda } 1 \text { Azul } \\
\text { Banda } 2 \text { Verde } \\
\text { Banda } 3 \text { Vermelho }\end{array}$ & $30 \mathrm{~m}$ & 8 bits \\
\hline 02/05/2016 & $\begin{array}{c}\text { Landsat } \\
8\end{array}$ & OLI & $\begin{array}{c}\text { Banda } 2 \text { Azul } \\
\text { Banda } 3 \text { Verde } \\
\text { Banda } 4 \text { Vermelho } \\
\text { Banda } 8 \text { Pancromática }\end{array}$ & $\begin{array}{l}30 \mathrm{~m} \\
15 \mathrm{~m}\end{array}$ & 16 bits \\
\hline
\end{tabular}

Fonte: Adaptado de USGS.

A preparação do banco de dados consistiu no pré-processamento das imagens com operações de correção atmosférica através do método FLAASH (AHMAD, 2016, p.1935), sendo 


\section{DINÂMICA DA ALTERAÇÃO DA COBERTURA VEGETAL E USO DA TERRA COM SUPORTE DE GEOTECNOLOGIA NA BACIA HIDROGRÁFICA DO RIO DESQUITE - SC}

que, para o Landsat 8/OLI foi possível ainda efetuar a fusão entre as imagens multiespectrais e a imagem pancromática, utilizando o método Gram-Schmidt, a fim de melhorar a resolução espacial. Tal método apresenta maior acurácia, pois utiliza a função de resposta espectral do sensor para simular a banda pancromática (ENVI, 2015, p.840), preservando, portanto, o conteúdo espectral da imagem original e melhorando sua definição de $30 \mathrm{~m}$ para $15 \mathrm{~m}$. As imagens de anos inferiores a 2016 não foram fusionadas devido à ausência da imagem pancromática nos satélites anteriores.

A classificação foi executada pelo modo supervisionado na abordagem pixel-a-pixel, que agrega as regiões por semelhança de pixels nas amostras coletadas e que definem as classes temáticas que podem ser reconhecidas na imagem através de princípios como cor, tonalidade, textura, forma, grupamento, tamanho e sombra (MOHAMMADY, 2015, p.1515; REIS, 2015, p. 61).

Devido à resolução espacial e a distribuição espacial dos alvos de interesse nas imagens, o fator espectral ou cor tende a ser mais importante na segmentação do que a forma, em auxílio a identificação observou-se alvos de geometria mais regular, como áreas urbanas, parcelas agrícolas e de reflorestamento, e outros de fronteiras irregulares, como florestas e campos (FRANCISCO, 2012, p.302). As amostras de treinamento ou conjunto de pixels representativos para cada classe definem um padrão de comportamento espectral para as feições (BECEGATO, 2007, p.217).

De acordo com as amostras coletadas, o classificador separa e identifica cada classe selecionada e rotula em uma categoria temática. Neste processo, foram escolhidas amostras representativas para as seguintes classes de uso e ocupação do solo: Mata Nativa - área ocupada por floresta nativa, em qualquer estágio de desenvolvimento; Silvicultura - área ocupada por cultivo de espécies de eucalipto ou pinus; Agricultura - área ocupada por qualquer tipo de cultivo, em período de colheita ou replantio; Campo - área formada por herbáceas, gramíneas e pequenos arbustos esparsos (nativo ou antrópico); Área urbanizada - área ocupada pelos centros dos municípios.

A área urbanizada foi recortada através de um polígono, pois a reflexão das ondas eletromagnéticas produz cores visíveis muito semelhantes à agricultura nas imagens de satélite.

$\mathrm{O}$ algoritmo classificador foi o Maximum Likelihood (MEDDENS, 2013, p.49; MOREIRA, 2013, p.58), que faz uso de uma função discriminante para atribuir ao pixel a classe com a mais alta probabilidade. Classe média do vetor e matriz de covariância são os principais insumos para a função e pode ser calculada a partir dos pixels de formação de uma classe particular (AHMAD, 2012, p.129). Uma técnica discreta multivariada de uso em avaliação de acurácia, o índice Kappa (K), representa o acordo perfeito entre as unidades analisadas ( $\mathrm{k}=1$ ), portanto os índices de exatidão dependem da amostragem empregada na geração dos dados de referência (ZHU, 2012, p.72; FONSECA, 2013,p.81; MEDDENS, 2013, p.49; MOREIRA, 2013, p.58; SEXTON, 2013, p.246; OLIVEIRA et al, 2015, p.322; POELKING, 2015, p.215). Os intervalos de aceitação, sugeridos por Congalton \& Green (2008, p.113), dos resultados do K, estão apresentados na Tabela 2.

Tabela 2 - Níveis de aceitação de $\mathrm{k}$

\begin{tabular}{lccc}
\hline Classificação & Pobre & Razoável & Excelente \\
\hline Índice Kappa $(\boldsymbol{k})$ & $\mathrm{K} \leq 0,4$ & $0,4<\mathrm{k} \leq 0,8$ & $\mathrm{~K} \geq 0,8$ \\
\hline
\end{tabular}

Fonte: Adaptado de Congalton \& Green, 2008.

Em ambiente SIG, foram realizados o mosaico das ortofotos e MDT para delimitação automática da bacia, mapa de declividade, cálculo das áreas dos usos classificados, 


\section{DINÂMICA DA ALTERAÇÃO DA COBERTURA VEGETAL E USO DA TERRA COM SUPORTE DE GEOTECNOLOGIA NA BACIA HIDROGRÁFICA DO RIO DESQUITE - SC}

delimitação das Áreas de Prevenção Permanente (APP) e elaboração de mapas temáticos.

Os usos classificados para a área da bacia foram comparados às APPs, a fim de identificar áreas que estavam em desacordo com o Código Florestal Brasileiro (Lei 12.651/2012). Devido à resolução espacial das imagens de satélite (Tabela 2) e à largura média da rede hidrográfica do rio Desquite (inferior a 10 metros), somente foi possível a comparação entre APP e classes de uso para a imagem do satélite Landsat 8/OLI. À imagem classificada de 2016 sobrepôs-se a rede hidrográfica consolidada para comparação das áreas de preservação permanente nas faixas marginais dos cursos d'água. A delimitação das APPs considerou o artigo 4으 do Código Florestal Brasileiro que determina a largura mínima de $30 \mathrm{~m}$, em zonas rurais e urbanas para estes cursos. O mesmo artigo diz ainda que devem ser reservadas áreas com raio de $50 \mathrm{~m}$ no entorno de nascentes e encostas com declividade superior a 45으 (BRASIL, 2012; CARVALHO, 2014, p.8).

O levantamento da situação em que se encontram as áreas de preservação permanente, relativamente ao que dita à legislação, foi feito para os cursos d'água e nascentes, pois, conforme se observa na Tabela 3 , a bacia não apresenta áreas relevantes com declividade acima de quarenta e cinco graus.
Realizou-se a validação dos resultados tendo como referência imagens do aplicativo Google Earth, ortofotos disponibilizadas pelo governo do estado de Santa Catarina (SDS, 2013) e fotos georreferenciadas das observações em campo.

A área de estudo, apresentada na Figura 2, está inserida, no contexto internacional, na bacia do rio da Prata e na bacia geológica do rio Paraná, distribuída em territórios do Brasil, Paraguai, Argentina e Uruguai. No contexto regional, integra a região hidrográfica do Planalto Lageano ou Região Hidrográfica 4 e compreende a bacia hidrográfica do rio Desquite, entre as coordenadas de Latitude 27ㅇ 25' e 27ㅇ 36' S e Longitude 49o 53' e 50 $07^{\prime} \mathrm{W}$, no município de Otacílio Costa, região serrana do Estado de Santa Catarina.

A bacia do rio Desquite possui $880 \mathrm{~m}$ de altitude média, sendo $935 \mathrm{~m}$ de altitude máxima na porção mais a leste da área e $825 \mathrm{~m}$ no exutório a oeste. $O$ curso principal tem extensão de $72,44 \mathrm{~km}$ com área de drenagem de aproximadamente $248 \mathrm{~km} 2$ e apresenta sua porção final em perímetro urbano. A importância deste rio deve-se a sua função de abastecimento de água para uma população urbana de aproximadamente 18.000 pessoas (IBGE, 2016). 


\section{DINÂMICA DA ALTERAÇÃO DA COBERTURA VEGETAL E USO DA TERRA COM SUPORTE DE GEOTECNOLOGIA NA BACIA HIDROGRÁFICA DO RIO DESQUITE - SC}

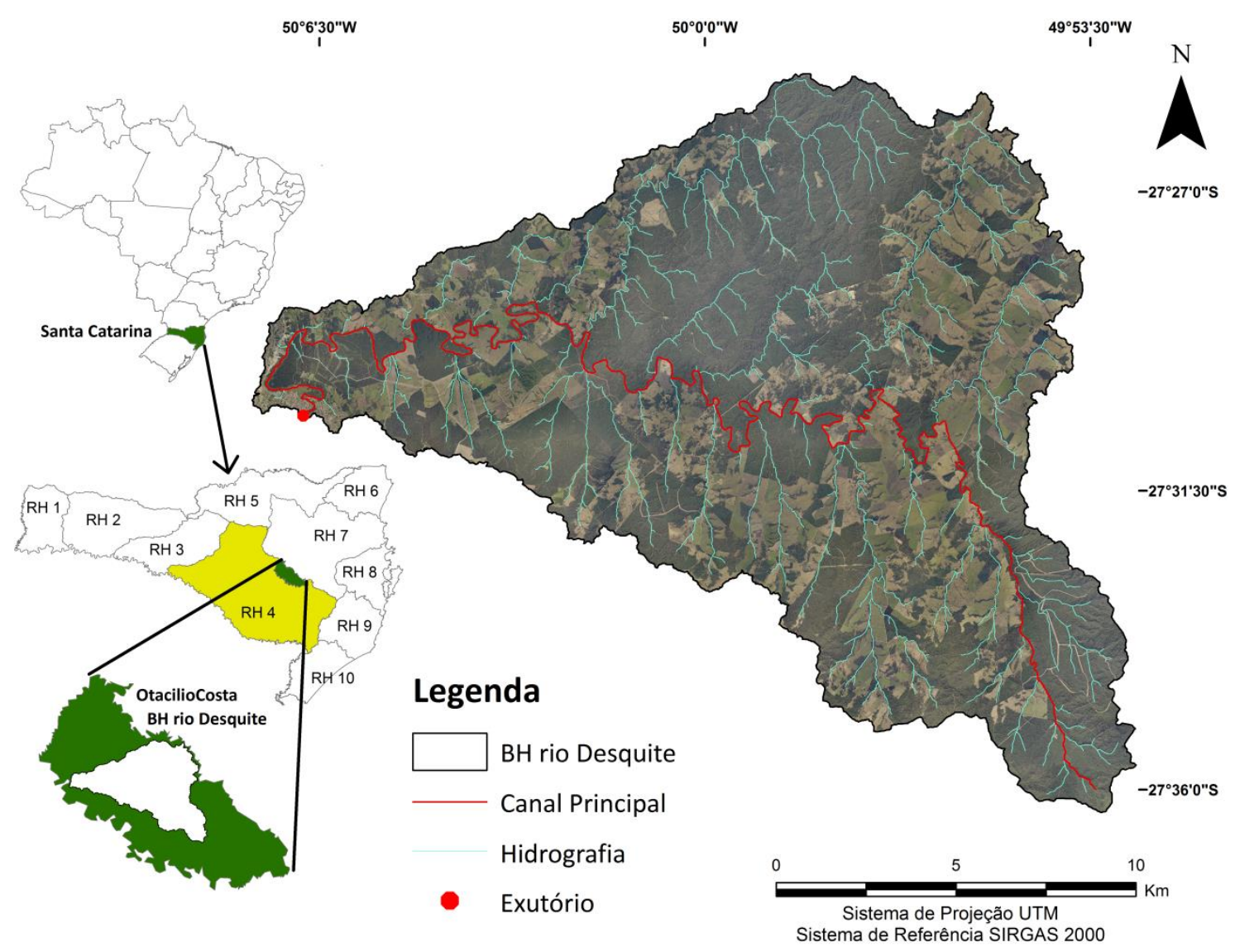

Figura 2 - Mapa de localização da bacia hidrográfica do rio Desquite, SC. Fonte: Autor.

As formas do relevo, definidas pela declividade, seguem a classificação sugerida pela EMBRAPA (1979) (Tabela 3) e apresentam variação, principalmente, entre plano e ondulado (Figura 3).

Tabela 3 - Classificação da declividade determinada pela Embrapa (1979).

\begin{tabular}{clcc}
\hline Declividade (\%) & \multicolumn{1}{c}{ Discriminação } & Área $\left(\mathbf{K m}^{\mathbf{2}}\right)$ & \% \\
\hline $0-3$ & Relevo plano & 71,96 & $28,96 \%$ \\
$3-8$ & Relevo suavemente ondulado & 46,09 & $18,55 \%$ \\
$8-20$ & Relevo ondulado & 99,37 & $39,99 \%$ \\
$20-45$ & Relevo fortemente ondulado & 21,06 & $8,48 \%$ \\
$45-75$ & Relevo montanhoso & 8,26 & $3,32 \%$ \\
$>75$ & Relevo fortemente montanhoso & 1,73 & $0,70 \%$ \\
\hline
\end{tabular}

Fonte: Adaptado de Embrapa, 1979 (p.27). 


\section{DINÂMICA DA ALTERAÇÃO DA COBERTURA VEGETAL E USO DA TERRA COM SUPORTE DE GEOTECNOLOGIA NA BACIA HIDROGRÁFICA DO RIO DESQUITE - SC}

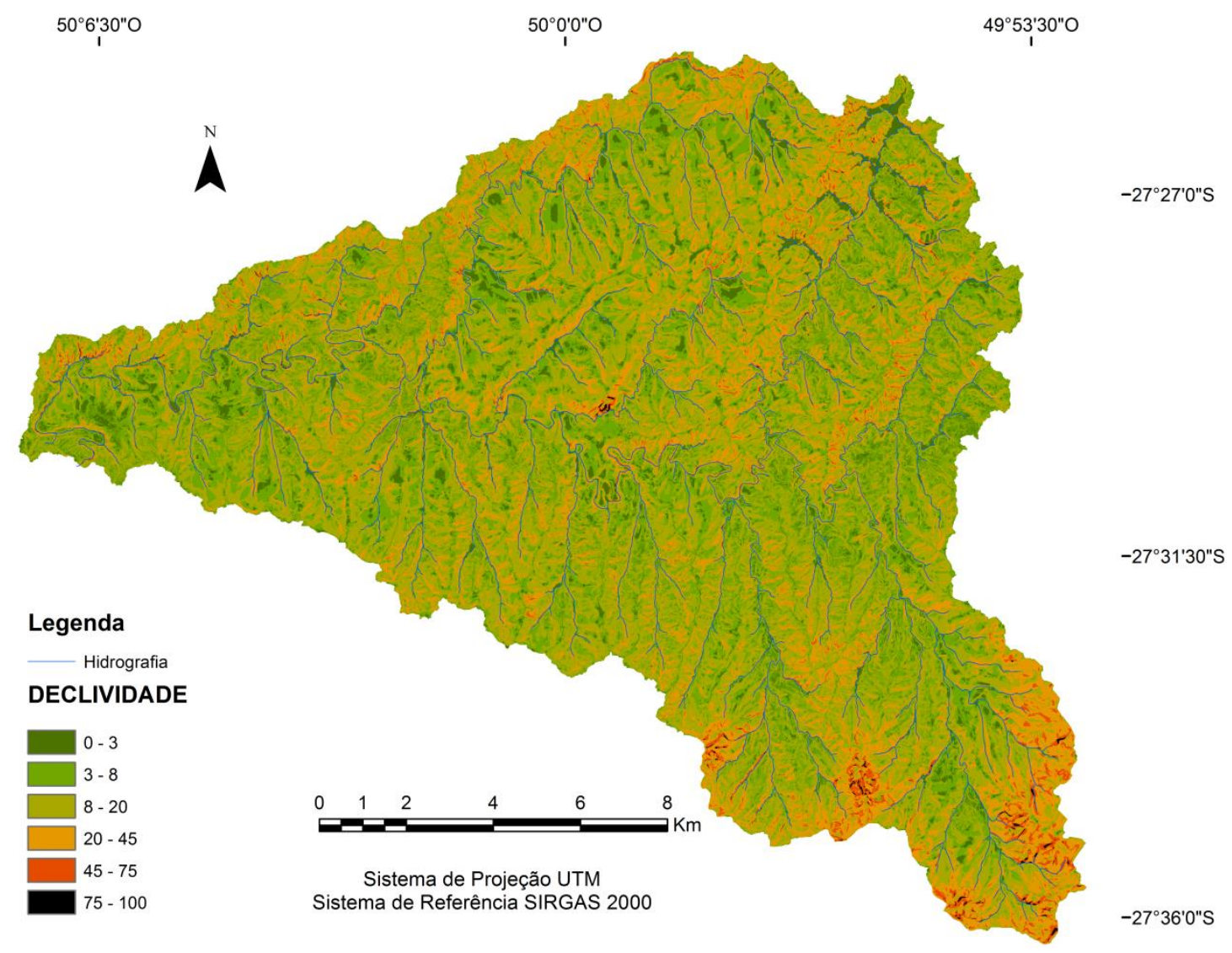

Figura 3 - Mapa de declividade de acordo com Embrapa (1979). Fonte: Autor

Segundo a classificação fitogeográfica de Klein (1978), as formações vegetais originalmente dominantes da região eram os Campos e a Floresta Ombrófila Mista, formação Montana (IBGE, 2012, p. 80), porém o processo histórico de ocupação de terras no planalto catarinense resultou na fragmentação florestal e em mudanças florísticas e estruturais na vegetação original, principalmente devido à intensa exploração madeireira e conversão destas áreas para atividades agropecuárias (MENEGATTI et al., 2014, p. 725; OLIVEIRA et al., 2016, p.95).

\section{RESULTADOS E DISCUSSÃO}

$O$ estudo foi realizado em um período de 40 anos, utilizando imagens obtidas a intervalos de dez anos: 1976, 1986, 1996, 2006 e 2016. Foram definidas cinco classes temáticas: agricultura, área urbanizada, campo, mata nativa e silvicultura. A classe corpo d'água foi excluída, pois a resolução das imagens, em relação às pequenas dimensões dos cursos, não permite que sejam corretamente identificados.

A visualização da evolução espacial do uso e ocupação da terra é apresentada na Figura 4. A Figura 5, expressa em área e percentagem relativa, evidencia as variações, com declínio das classes campo e mata nativa e o aumento da silvicultura e agricultura até 2006; no intervalo seguinte até 2016, a classe silvicultura apresenta leve decréscimo em detrimento a um pequeno acréscimo para a mata nativa, enquanto a classe agricultura mantem-se estável. As áreas de ocupação, dadas em $\mathrm{Km} 2$ e percentagem relativa, encontram-se na Tabela 4 , Os $\mathrm{K}$ obtidos apresentaram valores acima de 0,8 , classificação considerada excelente. 


\section{DINÂMICA DA ALTERAÇÃO DA COBERTURA VEGETAL E USO DA TERRA COM SUPORTE DE GEOTECNOLOGIA NA BACIA HIDROGRÁFICA DO RIO DESQUITE - SC}
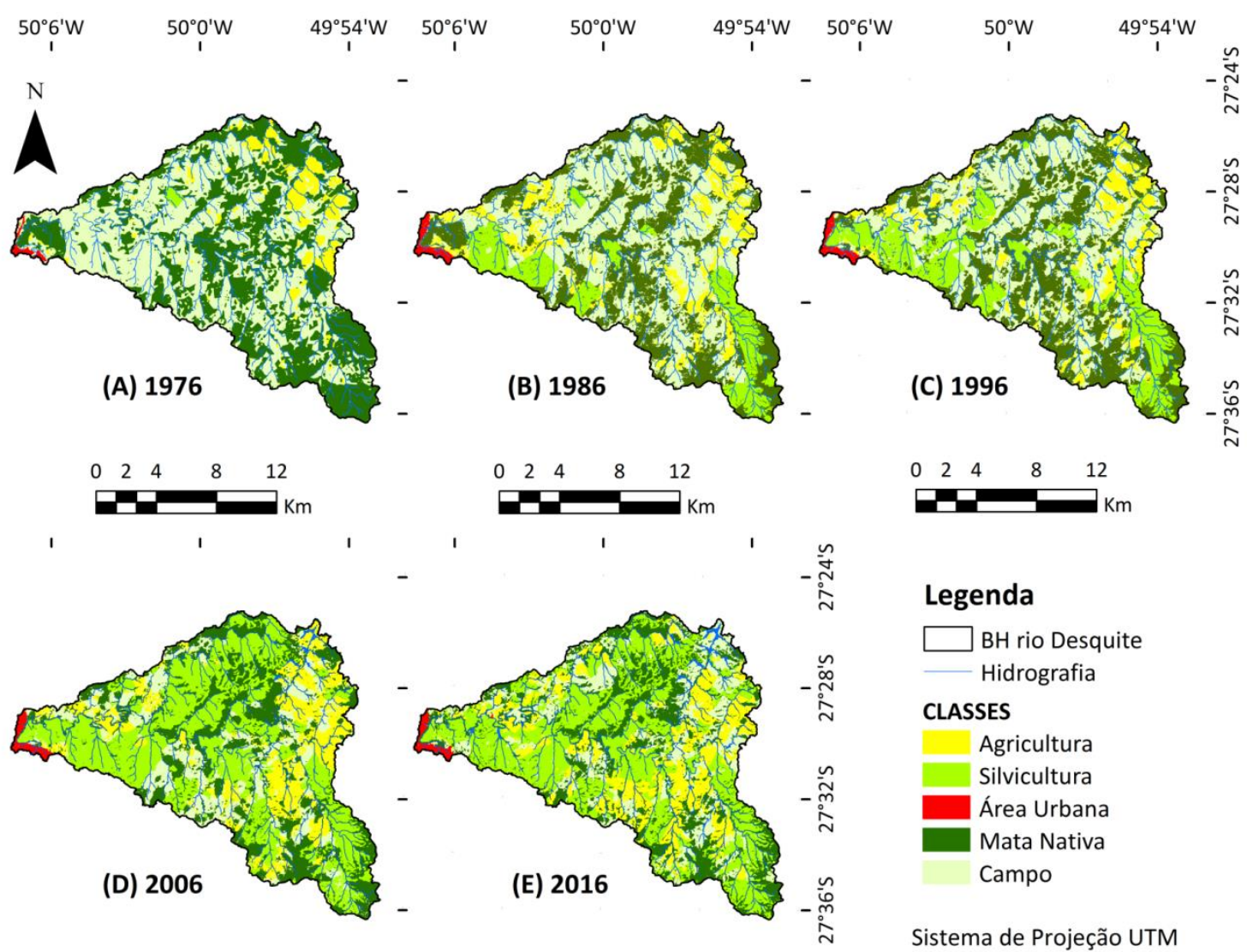

\section{Legenda}

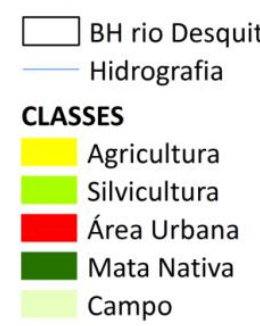

Sistema de Projeção UTM Sistema de Referência SIRGAS 2000

Figura 4 - Evolução do uso do solo na bacia hidrográfica do rio Desquite referente aos anos: 1976 (A), 1986 (B), 1996 (C), 2006 (D) e 2016 (E). Fonte: Autor

Tabela 4 - Principais usos do solo em $\mathrm{Km} 2$ e \% relativa

\begin{tabular}{|c|c|c|c|c|c|c|}
\hline \multirow[b]{2}{*}{ Ano } & \multicolumn{5}{|c|}{ Classe $\left[\mathrm{Km}^{2}\right.$ e $\%$ relativa] } & \multirow{2}{*}{$\begin{array}{l}\text { Índice } \\
\text { кappa }\end{array}$} \\
\hline & $\begin{array}{c}\text { Mata } \\
\text { Nativa }\end{array}$ & Campo & Área Urbanizada & Silvicultura & Agricultura & \\
\hline \multirow{2}{*}{1976} & 107,44 & 120,95 & 1,21 & 1,10 & 17,77 & \multirow{2}{*}{0,94} \\
\hline & $43,24 \%$ & $48,68 \%$ & $0,49 \%$ & $0,44 \%$ & $7,15 \%$ & \\
\hline \multirow{2}{*}{1986} & 87,39 & 91,69 & 2,05 & 29,45 & 36,96 & \multirow{2}{*}{0,87} \\
\hline & $35,17 \%$ & $36,90 \%$ & $0,82 \%$ & $11,85 \%$ & $14,87 \%$ & \\
\hline \multirow{2}{*}{1996} & 84,49 & 93,70 & 2,18 & 43,60 & 23,58 & \multirow{2}{*}{0,83} \\
\hline & $34,01 \%$ & $37,71 \%$ & $0,88 \%$ & $17,55 \%$ & $9,49 \%$ & \\
\hline \multirow{2}{*}{2006} & 65,97 & 42,46 & 2,22 & 96,19 & 40,16 & \multirow{2}{*}{0,85} \\
\hline & $26,55 \%$ & $17,09 \%$ & $0,89 \%$ & $38,71 \%$ & $16,16 \%$ & \\
\hline \multirow{2}{*}{2016} & 67,17 & 45,01 & 2,15 & 90,70 & 39,98 & \multirow{2}{*}{0,94} \\
\hline & $27,03 \%$ & $18,12 \%$ & $0,87 \%$ & $36,50 \%$ & $16,09 \%$ & \\
\hline
\end{tabular}

Fonte: Autor 


\section{DINÂMICA DA ALTERAÇÃO DA COBERTURA VEGETAL E USO DA TERRA COM SUPORTE DE GEOTECNOLOGIA NA BACIA HIDROGRÁFICA DO RIO DESQUITE - SC}

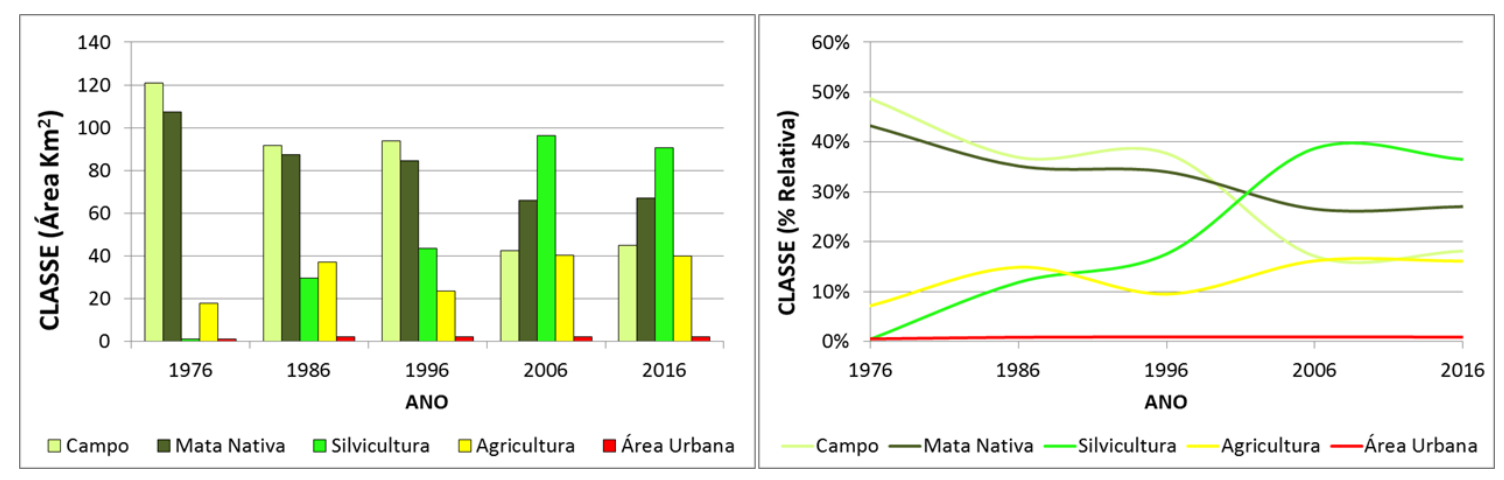

Figura 5 - Dinâmica do uso e ocupação do solo da bacia hidrográfica do rio Desquite. Fonte: Autor

No início do período de análise, no ano de 1976, predominavam, na área, as classes de mata nativa e campos (naturais ou antrópicos), com agricultura inexpressiva, pequena área urbana e a silvicultura em estágio inicial, pois às concessões de incentivos fiscais a empreendimentos comerciais na área florestal e a instalação de indústria papeleira ocorreram na década anterior. Após um período de dez anos, a silvicultura teve um crescimento para cerca de 29\% da área total, passando a ocupar áreas antes classificadas como campos e mata nativa. Resultado similar é encontrado por Sfredo \& Tagliani (2016, p.220) ao estudar as modificações ambientais no entorno da cidade de Rio Grande RS. Principalmente nas áreas de campos, o reflorestamento desenvolveu-se a uma taxa crescente até o ano de 2006, aceleradamente nos períodos entre 1986 até 2006, com uma taxa de $327 \%$ de crescimento, atingindo um total de $38,71 \%$ da área total da bacia em 2006. Na década entre 2006 e 2016, a taxa foi de leve decrescimento $(2,21 \%)$, associado provavelmente ao enquadramento das áreas de APPs inseridas nestas florestas e também à crise econômica no setor florestal em 2008 que levou alguns proprietários rurais a voltar para as atividades agropecuárias. A crise financeira e econômica mundial de 2008 e 2009 iniciou nos Estados
Unidos e afetou a maioria dos setores econômicos de vários países reduzindo as atividades econômicas. A demanda por produtos de madeira foi afetada, devido principalmente, a redução dos investimentos em construção civil, exigindo um ajuste da cadeia produtiva florestal (CAMARA SETORIAL DE SILVICULTURA, 2009; TOMASELLI, 2012, p.5).

As áreas correspondentes à mata nativa foram alteradas para as áreas de silvicultura, agricultura e urbanizada, sendo que a taxa de conversão para outros usos é crescente de 1976 a 2006, com uma taxa maior, no período compreendido entre 1996 e 2006. A partir do ano de 2006, percebe-se uma diminuição nessa taxa, o que pode ser explicado pela atualização do código florestal brasileiro (2012) e maior aplicação e fiscalização desta e das demais leis ambientais. A classe campo, apresentou perda de área para silvicultura e agricultura, mais notadamente entre 1996 e 2006, no período seguinte observou-se estabilização.

Foram consideradas áreas de conflito de uso aquelas em que a classe mata nativa, em trechos das margens da malha hidrográfica do rio Desquite, foi substituída pelas classes campo, área urbanizada, silvicultura e agricultura (Figura 6). 


\section{DINÂMICA DA ALTERAÇÃO DA COBERTURA VEGETAL E USO DA TERRA COM SUPORTE DE GEOTECNOLOGIA NA BACIA HIDROGRÁFICA DO RIO DESQUITE - SC}
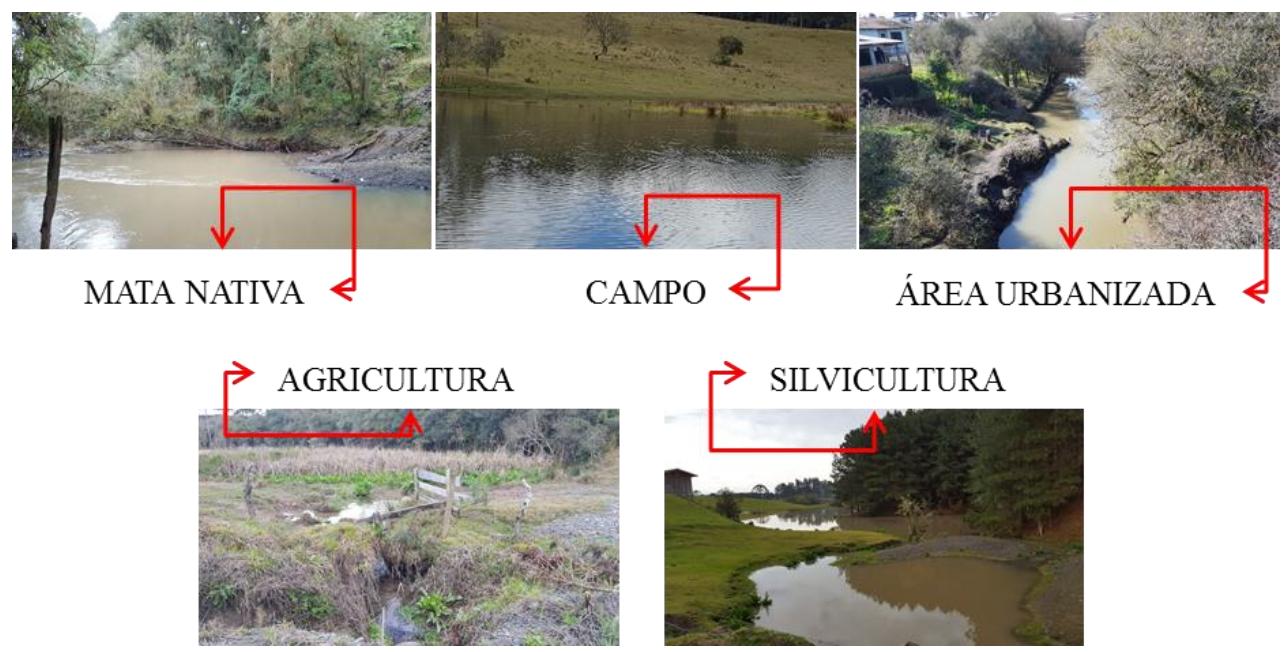

Figura 6 - Exemplos dos tipos de uso e ocupação que ocorrem nas APPs da bacia hidrográfica do rio Desquite. Fonte: Autor.

Como resultado da análise do mapa de uso do solo em APPs (Figura 6), constata-se que da área total de 248,47 Km2, são enquadrados como APPs, $24,87 \mathrm{Km} 2(10,01 \%)$, sendo que destas, 13,90 Km2 apresentam conflito de uso (Lei $n^{\circ} 12.651 / 12$ ), ou seja, $55,90 \%$ das faixas marginais estão ocupadas com classes diversas da mata nativa.

A Figura 7 e a Tabela 5, a seguir, apresentam respectivamente: os resultados quantitativos obtidos para cada uma das classes e o mapa de usos do solo nas APPs.

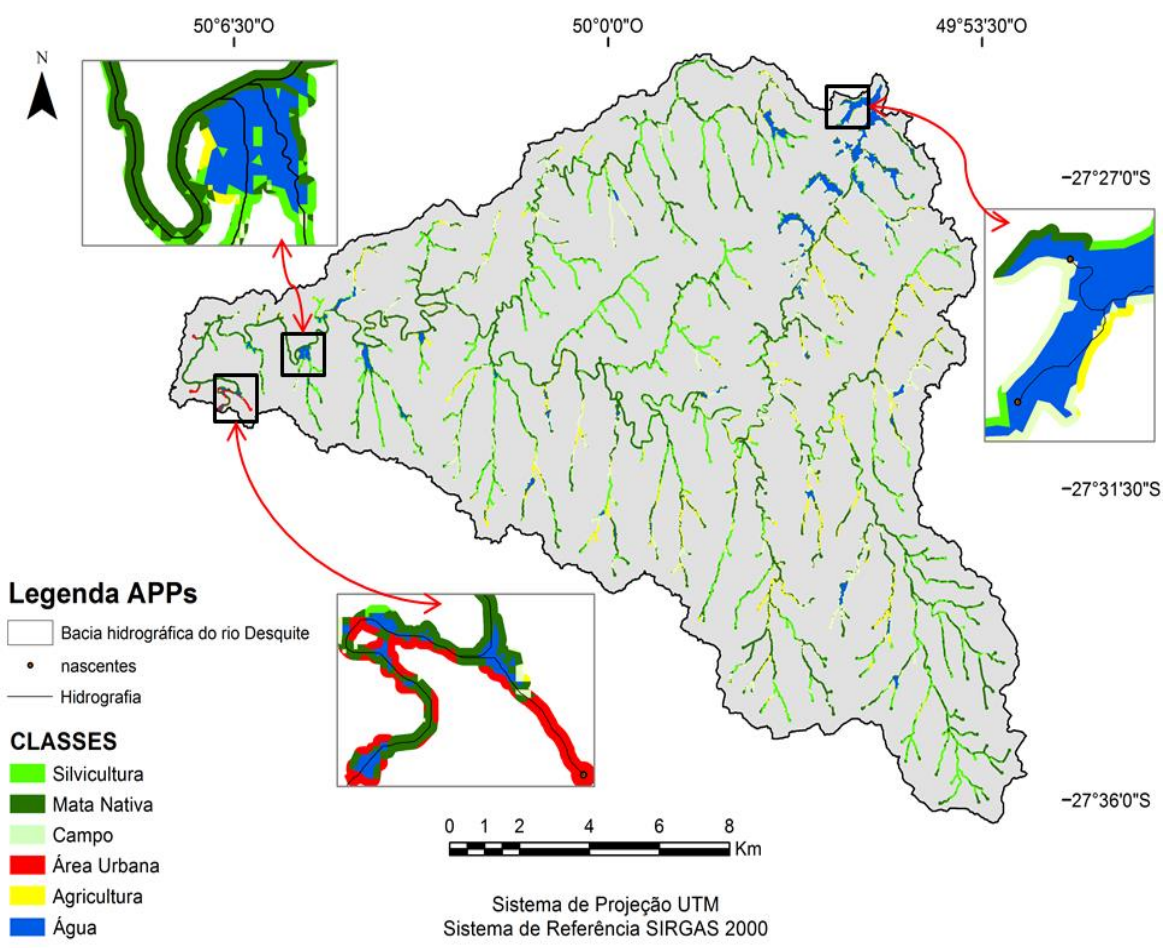

Figura 7 - Uso do solo das Áreas de Preservação Permanente na bacia hidrográfica do rio Desquite. Fonte:

Autor 


\section{DINÂMICA DA ALTERAÇÃO DA COBERTURA VEGETAL E USO DA TERRA COM SUPORTE DE GEOTECNOLOGIA NA BACIA HIDROGRÁFICA DO RIO DESQUITE - SC}

Tabela 5 - Usos do solo nas APPs das faixas marginais dos cursos d'água e nascentes.

\begin{tabular}{|c|c|c|c|c|c|c|}
\hline \multirow[b]{2}{*}{ Ano } & \multicolumn{5}{|c|}{ Classe sobre APP [ $\mathrm{Km}^{2}$ e $\%$ relativa] } & \multirow{2}{*}{$\begin{array}{l}\text { Total de } \\
\text { APP }\left[\mathrm{Km}^{2}\right]\end{array}$} \\
\hline & Mata Nativa & Campo & $\begin{array}{c}\text { Área } \\
\text { Urbanizada }\end{array}$ & Silvicultura & Agricultura & \\
\hline \multirow{2}{*}{2016} & 10,97 & 4,24 & 0,11 & 7,22 & 2,33 & \multirow{2}{*}{24,87} \\
\hline & $44,10 \%$ & $17,07 \%$ & $0,45 \%$ & $29,03 \%$ & $9,35 \%$ & \\
\hline \multirow{2}{*}{\multicolumn{6}{|c|}{ Total de conflitos de uso em Áreas de Preservação Permanente: }} & 13,90 \\
\hline & & & & & & $55,90 \%$ \\
\hline
\end{tabular}

Fonte: Autor

O predomínio é da classe silvicultura que ocupa 7,22 Km2 ou 29,03\% do total de conflitos, seguido pela classe campo com $4,24 \mathrm{Km} 2$ ou $17,07 \%$ e em menor porcentagem, as classes agricultura e área urbanizada com 2,33 $\mathrm{Km} 2$ $(9,35 \%)$ e $0,11 \mathrm{Km} 2(0,45 \%)$ respectivamente.

$\mathrm{Na}$ análise do conflito de uso com a silvicultura é possível inferir que esta vem ajustando-se as regras impostas pelo novo código florestal conforme acontecem as colheitas, pois as duas espécies exóticas plantadas têm ciclo superior a 10 anos. Em locais onde os replantios aconteceram recentemente, observa-se um recuo referente às APPs, entretanto, a grande maioria delas encontra-se em processo de regeneração natural e foram classificadas na categoria campo.

O uso conflitante por campo explica-se com o desmatamento histórico desta região, além disso, alguns produtores rurais mantêm estas áreas como acessos dos animais ao rio para dessedentação, salientando-se que embora as leis tenham enrijecido quanto às regras de uso e ocupação do solo, o processo de recuperação destas ainda não iniciaram de forma efetiva. Nesse contexto, a utilização das APPs com atividades agropecuárias, pode ser um fator de comprometimento do uso sustentável da água e do solo, principalmente ao se considerar a dependência da agropecuária pela disponibilidade quantitativa e qualitativa destes recursos (COUTINHO, 2013, p.425).

A área urbanizada coloca-se menos significante em termos quantitativos, porém é importante observar que a pressão das áreas urbanas, associada à ausência de coleta e tratamento das águas residuárias no município, resulta em despejos diretos nos cursos d'água, ocasionando a degradação do recurso hídrico. Observou-se também o descarte de resíduos sólidos nestas regiões e a proximidade das edificações em relação às APPs tornando-as vulneráveis a ocorrência de enchentes. Na Figura 7, a seguir, exemplifica-se tais situações: em (a) e (b) há canalização pluvial carregada com efluentes domésticos, em (c) e (d) edificações residenciais e comerciais construídas às margens do rio, em (e) resíduos de oficina mecânica na barranca e, em (f), local a poucos metros antes do ponto de captação de água pela concessionária, responsável pelo abastecimento de água a população do município, observa-se além de sacos de lixo a carcaça de um animal morto (em destaque). 


\section{DINÂMICA DA ALTERAÇÃO DA COBERTURA VEGETAL E USO DA TERRA COM SUPORTE DE GEOTECNOLOGIA NA BACIA HIDROGRÁFICA DO RIO DESQUITE - SC}
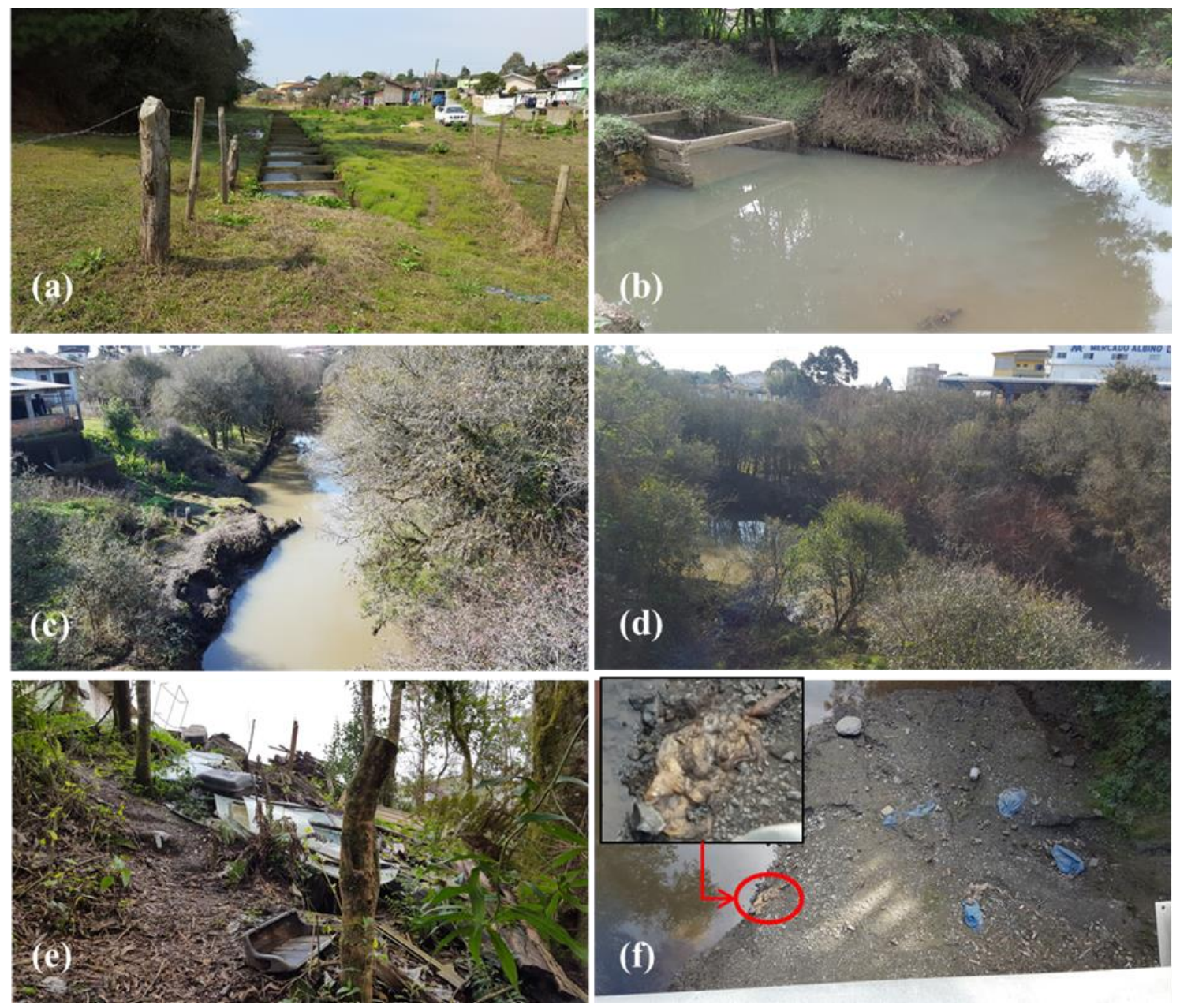

Figura 7 - Pressão antrópica sobre o rio Desquite. Fonte: Autor

\section{CONCLUSÃO}

O uso de técnicas de processamento digital de imagens orbitais mostrou-se eficiente na estimativa da dinâmica temporal do uso e ocupação da terra.

Constatou-se uma redução progressiva das áreas de vegetação nativa e o avanço principalmente das áreas destinadas à silvicultura, inclusive no entorno de cursos d'água. A evolução da alteração do uso do solo aconteceu de forma acelerada entre 1976 e 2006.

Como resultado da análise de conflitos de uso em APPs, obteve-se que $55,90 \%$ das faixas marginais de cursos d'água estão ocupadas com classes diversas da mata nativa.

Observou-se também o descarte de resíduos sólidos nas proximidades dos corpos hídricos em toda extensão da bacia e a proximidade de edificações em relação às APPs tornando-as vulneráveis a ocorrência de enchentes.

Os resultados deste trabalho indicam a importância de sua continuidade no estudo dos possíveis impactos na qualidade da água que será utilizada para o abastecimento público.

\section{REFERÊNCIAS BIBLIOGRÁFICAS}

AHMAD, A.; QUEGAN, S. Analysis of maximum likelihood classification on multispectral data. Applied Mathematical Sciences, Rousse, v. 6, n. 129-132, p. 6425-6436, 2012.

AHMAD, A.; QUEGAN, S. The Effects of Haze on the Accuracy of Maximum Likelihood Classification. Applied Mathematical Sciences, Rousse, v. 10, n. 39, p. 1935-1944, 2016.

BECEGATO, V.A.; FERREIRA, F.J.F.; CABRAL, J.B.P.; FIGUEIREDO, O.A.R.; NETO, S.L.R. (2007). 


\section{DINÂMICA DA ALTERAÇÃO DA COBERTURA VEGETAL E USO DA TERRA COM SUPORTE DE GEOTECNOLOGIA NA BACIA HIDROGRÁFICA DO RIO DESQUITE - SC}

Monitoramento do uso e ocupação do solo em área de influência do município de fazenda rio grande-região metropolitana de Curitiba-PR. Raega - O Espaço Geográfico em Análise, Curitiba, n. 14, p. 217-227, Editora UFPR, 2007.

BRASIL. Lei no 9.433, de 8 de janeiro de 1997. Institui a Política Nacional de Recursos Hídricos, cria o Sistema Nacional de Gerenciamento de Recursos Hídricos e dá outras providencias. Diário Oficial [da] República Federativa do Brasil, Brasília, DF, 18 mar. 2005.

BRASIL. Lei no 12.651, de 25 de maio de 2012. Dispõe sobre a proteção da vegetação nativa. Código Florestal: Legislação Federal. Brasília, DF, Disponível em: <http://www.planalto.gov.br/ccivil_03/_ato20112014/2012/lei/l12651.htm>, Acesso em: $19 / 09 / 2015$.

CAMARA SETORIAL DE SILVICULTURA. Agenda estratégica do setor de florestas plantadas. Brasília, DF, 2009.

CAMPOS, A.R.; FONSECA, D.F.; SAMPAIO, D.M.; FARIA, S.D.; ELMIRO, M.A.T. Classificação orientada à objeto para mapeamento do uso e cobertura do solo do município de Rio Acima, MG: por crescimento de regiões e por extração de objetos. Anais XVI Simpósio Brasileiro de Sensoriamento Remoto - SBSR, Foz do Iguaçu: INPE, p. 8035-8042, 2013.

CARVALHO, A.W.; SILVA, E. Utilização de sistemas de informação geográfica para mapeamento de áreas de preservação permanente - microbacia rio Peterstrasse, Brusque/SC. Anais do SNPD. Volume 2, Número 2. Florianópolis: Programa de Pós-Graduação em Planejamento e Governança Pública - PPGPGP, 2014.

CONGALTON, R. G.; GREEN, K. Assesing the accuracy of remotely sensed data: principles and practices. Boca Raton, CRC Press, 2008.

COSTA, C., COSTA, A., TEIXEIRA, A.D.S., ALVES, N.D.L., ANDRADE, E.D., SOUSA, B., LEÃO, A.D.O. Comparação do uso do SRTM para delimitação e caracterização fisiográfica de uma micro-bacia hidrográfica. Anais XIII Simpósio Brasileiro de Sensoriamento Remoto, Florianópolis: INPE, 2126, 2007.

COUTINHO, L.M.; ZANETTI, S.S.; CECÍLIO, R.A.; GARCIA, G.O.; XAVIER, A. C. Usos da Terra e Áreas de Preservação Permanente (APP) na Bacia do
Rio da Prata, Castelo-ES. Floresta e Ambiente, Seropédica, 20(4), 425-434, 2013.

EMPRESA BRASILEIRA DE PESQUISA AGROPECUÁRIA - EMBRAPA. Serviço Nacional de Levantamento e Conservação de Solos (Rio de Janeiro, RJ). Súmula da 10ㅇ Reunião Técnica de Levantamento de Solos. Rio de Janeiro, 1979.

ENVI. ENVI User's Guide - ENVI Version 5.3. Exelis Visual Information Solutions. 2015.

FONSECA, R.; SILVA, P.; SILVA, R. Acordo interjuízes: O caso do coeficiente kappa. Laboratório de Psicologia, Lisboa, v. 5, n. 1, p. 81-90. 2013.

FRANCISCO, C. N.; ALMEIDA, C.M. Evaluating the performance of statistical and textural attributes for an object-based land cover classification. Boletim de Ciências Geodésicas, Curitiba, v. 18, n. 2, p. 302-326, 2012.

INSTITUTO BRASILEIRO DE GEOGRAFIA E ESTATÍSTICA - IBGE. Manual Técnico da Vegetação Brasileira. 2a ed. Rio de Janeiro, 275p, 2012.

INSTITUTO BRASILEIRO DE GEOGRAFIA E ESTATISTICA - IBGE. Manual Técnico de Uso da Terra. 3a edição. Rio de Janeiro. 2013.

IBGE - INSTITUTO BRASILEIRO DE GEOGRAFIA E ESTÁTISTICA (Brasil). Santa Catarina: Otacílio Costa. 2016. Disponível em: <http://www.cidades.ibge.gov.br/xtras/perfil.php ?lang=\&codmun=421175 >. Acesso em: 25 out. 2016.

MANTOVANI, L. E., FRITZSONS, E., \& WREGE, M. $S$. Aspectos hidrológicos e hidrogeológicos da bacia do rio Fervida, aquífero Carste, Colombo, Paraná. Raega - O Espaço Geográfico em Análise, Curitiba, 37, 190-206, 2016.

MEDDENS, A.J.; HICKE, J.A.; VIERLING, L.A.; HUDAK, A.T. Evaluating methods to detect bark beetle-caused tree mortality using single-date and multi-date Landsat imagery. Remote Sensing of Environment, Amsterdam, 132, 49-58, 2013.

MENEGATTI, R. D.; HIGUCHI, P.; DA SILVA, A. C.; FERT-NETO, J.; CORREIA, J.; MUNARETTI, A. M. \& BERRI, P. Relação etnobotânica dos proprietários rurais do município de Urupema, SC, com recursos florestais. FLORESTA, Curitiba, v. 44, n. 4, p. 725-734, 2014.

MOHAMMADY, M.; MORADI, H.R.; ZEINIVAND, H.; TEMME, A. J. A. M. A comparison of supervised, unsupervised and synthetic land use 


\section{DINÂMICA DA ALTERAÇÃO DA COBERTURA VEGETAL E USO DA TERRA COM SUPORTE DE GEOTECNOLOGIA NA BACIA HIDROGRÁFICA DO RIO DESQUITE - SC}

classification methods in the north of Iran. International Journal of Environmental Science and Technology, New York, 12(5), 1515-1526, 2015.

MOREIRA, G.F. Classificação Automatizada do Uso e Cobertura do Solo a Partir de Imagens Landsat (Automated Classification of Use and Land Cover from Landsat Images). Revista Brasileira de Geografia Física, Recife, v. 6, n. 1, p. 058-065, 2013.

MOREIRA, T.R.; SANTOS, A.R.D.; DALFI, R.L.; CAMPOS, R.F.D.; SANTOS, G.M.A.D. A.D. \& EUGENIO, F.C. Confronto do Uso e Ocupação da Terra em APPs no Município de Muqui, ES. Floresta e Ambiente, Seropédica, v. 22, n. 2, p.141-152, 2015.

OLIVEIRA, F.P.; FILHO, E.I.F.; SOUZA, A.L.; SOARES, V.P. Mapeamento de Florestas Monodominadas por Myracrodruon urundeuva com Imagens TM-Landsat 5 e Rapideye. Floresta e Ambiente, Seropédica, 22(3), 322-333, 2015.

OLIVEIRA, J.C. Caracterização ambiental da bacia hidrográfica do Rio Ponte Grande no município de Lages-SC. 152P. Dissertação (mestrado) Universidade do Estado de Santa Catarina, Centro de Ciências Agroveterinárias, Programa de PósGraduação em Produção Vegetal, Lages, 2015.

OLIVEIRA, J.C.; BAUM, C.A.; BECEGATO, V.A.; NETO, S.L.R.; LAVNITCKI, L. Uso de ferramentas sig para análise de agrupamento florestal de Araucaria angustifolia em um fragmento de floresta ombrófila mista no parque nacional de São Joaquim-SC. Revista Geográfica Acadêmica, Boa Vista, v. 10, n. 2, 2016.

PINTO, L.V.A.; FERREIRA, E.; BOTELHO, S.A.; DAVIDE, A.C. Caracterização física da bacia hidrográfica do ribeirão Santa Cruz, Lavras, MG e uso conflitante da terra em suas áreas de preservação permanente. Cerne, Lavras, 11(1), 49-60, 2005.

POELKING, E. L., DALMOLIN, R. S. D., DE ARAÚJO PEDRON, F., \& FINK, J. R. Sistema de Informação Geográfica aplicado ao levantamento de solos e aptidão agrícola das terras como subsídios para o planejamento ambiental do município de Itaara, RS. Revista Árvore, Viçosa, 39(2), 215-223, 2015.

PRINA, B.Z.; MONGUILHOTT, M. Análise das transformações da paisagem de áreas próximas ao rio Jaguari aplicando técnicas de sensoriamento remoto em imagens do satélite TM Landsat-5. In: SIMPÓSIO BRASILEIRO DE SENSORIAMENTO REMOTO, 15. (SBSR), Curitiba. Anais XV Simpósio Brasileiro de Sensoriamento Remoto - SBSR. São José dos Campos: INPE. p. 3812-3818, 2011.

REIS, J.B.C.; SAAVEDRA, O.F.C. Comparação de métodos de classificação para reconhecimento de corpos d'água em imagens do sensor OLI do Landsat8. Anais XVII Simpósio Brasileiro de Sensoriamento Remoto - SBSR, João Pessoa: INPE, 25 a 29 de abril de 2015.

SEXTON, J.O.; URBAN, D.L.; DONOHUE, M.J.; SONG, C. Long-term land cover dynamics by multi-temporal classification across the Landsat- 5 record. Remote Sensing of Environment, Amsterdam, 128, 246-258, 2013.

SFREDO, G.A.; TAGLIANI, C.R.A. Análise das modificações ambientais decorrentes da ocupação urbana em Rio Grande, RS, entre 1947 e 2014, por meio de um Sistema de Informações Geográficas. Desenvolvimento e Meio Ambiente, Curitiba, v. 38, p. 213-230, 2016.

TOMASELLI I.; HIRAKURI S. A influência da crise econômica e financeira global no setor florestal do Brasil. Revista Informativo STCP, Curitiba volume 15: 5-11, 2012.

YUAN, F.; SAWAYA, K. E.; LOEFFELHOLZ, B. C.; BAUER, M. E. Land cover classification and change analysis of the Twin Cities (Minnesota) Metropolitan Area by multitemporal Landsat remote sensing. Remote Sensing of Environment, Amsterdam, v. 98, 317-328, 2005.

ZHU, Z.; WOODCOCK, C.E., ROGAN, J., KELLNDORFER, J. (2012). Assessment of spectral, polarimetric, temporal, and spatial dimensions for urban and peri-urban land cover classification using Landsat and SAR data. Remote Sensing of Environment, Amsterdam, 117, 72-82,2012. 